\title{
PENGARUH PIJAT REFLEKSI KAKI TERHADAP KUALITAS TIDUR ANAK 6-10 TAHUN \\ (Di Rumah Sakit Umum Daerah Sultan Imanuddin Pangkalan Bun)
}

\author{
M.Arif Jazuli ${ }^{1}$ Christina T.Setiawan ${ }^{2}$ Rahaju Wiludjeng ${ }^{3}$ \\ ${ }^{1}$ STIKes Insan Cendekia Medika Jombang ${ }^{23}$ STIKes Borneo Cendekia Medika \\ Pangkalan Bun \\ 1email : arifjazuli@gmail.com, ${ }^{2}$ email : csetiawan366@gmail.com, ${ }^{3}$ email : \\ ira.wiludjeng@gmail.com
}

\begin{abstract}
ABSTRAK
Pendahuluan: Tidur amatlah penting bagi anak saat menjalani proses pengobatan dirumah sakit sehingga ketika anak kualitas tidurnya tercukupi maka secara tidak langsung akan membantu proses penyembuhan ketika anak kualitas tidurnya tidak tercukupi akan menganggu proses penyembuhan.Pijat sebagai warisan turun temurun yang telah dilakukan hingga sekarang, Pijat salah satu bentuk terapi yang dapat di aplikasikan terhadap anak dan dapat merilekskan tubuh. Penelitian ini bertujuan untuk menganalisa pengaruh pijat refleksi kaki terhadap kualitas tidur anak 6-10 tahun. Metode penelitian: Desain penelitian ini menggunakan quasi experiment disign dengan pendekatan non-equivalent control group pada anak di Rumah Sakit Umum Daerah Sultan Imanuddin Pangkalan Bun jumlah responden ada 20 diruangan anak dengan teknik accidental sampling. Teknik analisis bivariat dengan menggunakan uji Rank Spearman dan distribusi frekuensi univariat (kualitas tidur).Metode pengumpulan data menggunakan lembar kuesioner untuk variabel kualitas tidur. Hasil penelitian: Hasil pengujian statistik dengan menggunakan Rank Spearman Tes diperoleh nilai $\mathrm{P}=0,033$ (lihat lampiran) pada penelitian ini digunakan derajat eror $\alpha<0,05$. P dibanding nilai $\alpha$ diperoleh $\mathrm{P}<\alpha$, maka Ho ditolak dan H1 diterima artinya ada Pengaruh Pijat Refleksi Kaki Terhadap Kualitas Tidur Pada Anak Usia 6-10 Tahun di Rumah Sakit Sultan Imanuddin Pangkalan Bun. Kesimpulan: Berdasarkan hal tersebut maka dapat disimpulkan bahwa terdapat pengaruh pijat refleksi kaki terhadap kualitas tidur pada anak usia 6-10 tahun di Rumah Sakit Umum Daerah Sultan Imanuddin Pangkalan Bun.
\end{abstract}

Kata kunci: Anak,Kualitas Tidur,Refleksi Kaki.

\section{EFFECTS OF FOOTWEAR REFLECTIONS TO QUALITY OF SLEEP 6-10 YEARS \\ (At the Regional General Hospital of Sultan Imanuddin Pangkalan Bun)}

\begin{abstract}
Introduction: Sleep is very important for the child while undergoing the treatment process in the hospital so that when the child's sleep quality is fulfilled then indirectly will help the healing process when the child is not sufficient quality of sleep will disturb the healing process. Massage as a hereditary heritage that has been done until now, Massage one form of therapy that can be applied to the child and can relax the body. This study aims to analyze the effect of foot reflexology on the quality of sleep for children 6-10 years. Research method: This research design
\end{abstract}


uses quasi experiment disign with non-equivalent control group approach in children at General Hospital of Sultan Imanuddin Pangkalan Bun area, there are 20 respondents of children with accidental sampling technique. Bivariate analysis technique using Rank Spearman test and univariate frequency distribution (sleep quality). Data collection method using questionnaire sheet for sleep quality variable. Result of research: The result of statistical test by using Rank Spearman Test obtained $P$ value $=0,033$ ( see attachment) in this research used eror $\alpha<0,05$. $P$ compared to the value of $\alpha$ obtained $P<\alpha$, then $H o$ is rejected and $H 1$ accepted means no Effect of Foot Reflexology on Sleep Quality At the age of 6-10 years at Sultan Imanuddin Pangkalan Bun Hospital. Conclusion: Based on this matter, it can be concluded that there is influence of foot reflexology massage to sleep quality in children aged 6-10 years at the Regional General Hospital of Sultan Imanuddin Pangkalan Bun.

Keywords: Child, ,Sleep Quality, Reflection Feet.

\section{PENDAHULUAN}

Banyaknya pasien yang berdatangan untuk berobat maupun hanya memeriksakan kesehatannya di rumah sakit, dan tidak banyak juga pasien yang rawat inap maupun rawat jalan salah satunya adalah pasien anak. Dari sekian banyaknya pasien terdapat banyak ruangan yang tersedia bagi pasien dari balita hingga dewasa yang semuanya telah tersedia di rumah sakit. Dari sekian banyaknya rungan yang tersedia salah satunya adalah ruangan anak yang tersedia di rumah sakit, tidaklah heran di setiap ruangan banyak masalah yang timbul termasuk di ruangan anak salah satunya seringkali di ruangan anak timbul masalah keperawatan salah satunya adalah masalah ganguan tidur pada anak karena nantinya akan menyebabkan kualitas tidur anak menjadi terganggu. Ketika anak mengalami gangguan tidur maka kualitas tidur anak akan terganggu sehingga proses untuk penyembuhan juga akan terganggu karena tidur merupakan salah satu kebutuhan dasar manusia. Tidur amatlah penting bagi anak saat menjalani proses pengobatan di rumah sakit sehingga ketika anak kualitas tidurnya tercukupi maka secara tidak langsung akan membantu proses penyembuhan. Pijat sebagai warisan turun temurun yang telah dilakukan hingga sekarang, Pijat salah satu bentuk terapi yang dapat di aplikasikan terhadap anak dan dapat merilekskan tubuh.

Data pada tahun 2014 penduduk Indonesia yang berumur 0-17 tahun mencapai 82,8 juta atau sebesar 32,9 persen dari keseluruhan penduduk. Kementerian Pemberdayaan Perempuan dan Perlindungan Anak (KPP dan PA, 2015). Jumlah anak di indonesia usia sekolah setingkat sekoalah dasar laki-laki sebesar 14.040.775 jiwa dan perempuan 13.340.905 jiwa jumlah total keseluruhan sebesar 27.381.680 jiwa (Kemenkes RI, 2015).

Dari masalah yang ada di rumah sakit di ruangan anak banyak masalah yang sering timbul, yang salah satunya di ruangan anak masalah keperawatan yang sering timbul adalah tentang gangguan tidur yang sering dialami oleh anak-anak di rumah sakit. Banyak 
faktor yang di alami oleh anak yang menyebabkan anak mengalami masalah gangguan tidur. Proses hospitalisasi pada anak dapat mengalami berbagai kejadian yang ditunjukkan dengan pengalaman yang traumatik dan penuh dengan stres. Bagi anak yang baru pertama kali dirawat biasanya menjalani lebih banyak tindakan pemeriksaan oleh beberapa orang, tidak pernah mempunyai gambaran tentang dirawat di rumah sakit, perubahan lingkungan yang tiba-tiba, staf yang masih sangat asing, menimbulkan stres tersendiri bagi anak (Perry \& Potter, 2005). Pijat sebagai salah satu terapi yang dapat membuat tubuh menjadi rileks dan nyaman sehingga dapat diaplikasikan terhadap anak yang sedang menjalani proses penyembuhan.

Jadi, dari uraian di atas peneliti ingin mengetauhi pengaruh pijat refleksi itu sebagai salah satu terapi bagi anak yang mengalami gannguan tidur. Sehingga peneliti ingin mengambil penelitian tentang " Pengaruh Pijat Refleksi kaki Terhadap Kualitas tidur Pada Anak Usia 6-10 Tahun Di Rumah Sakit Umum Daerah Sultan Imanudin Pangkalan Bun".

\section{METODE PENELITIAN}

Desain penelitian ini menggunakan quasi experiment disign dengan pendekatan non-equivalent control group (Notoatmodjo, 2014). Populasi merupakan gambaran umum berupa subjek ataupun objek yang sesuai dengan karakter tertentu dengan tujuan untuk mencari data agar nantinya dapat diperoleh kesimpulan penelitian (Sugiyono, 2011). Populasi semua pasien anak diruangan Lanan di Rumah Sakit Imanuddin Pangkalanbun teknik sampling yang digunakana adalah sampling accidental sampling. Sampel yang diperoleh sebanyak 20 anak. Alat pengambilan data menggunakan lembar observasi dan kuesioner. Analisa data menggunakan uji Rank Spearman $(\alpha=0,05$. $)$

\section{HASIL PENELITIAN}

\section{Data Umum}

Gambaran umum umur responden diruangan anak dirumah sakit sultan imanuddin pangkalan bun dapat dilihat pada tabel 1

Tabel 1 Distribusi responden berdasarkan umur

\begin{tabular}{cccc}
\hline No & Usia & Jumlah & Prensentase \\
\hline $\mathbf{1}$ & 6-8 tahun & 8 & $40 \%$ \\
$\mathbf{2}$ & $9-10$ tahun & 12 & $60 \%$ \\
$\mathbf{3}$ & Total & 20 & $100 \%$ \\
\hline
\end{tabular}

Dari tabel diatas diketahui sebagian besar dari responden berumur 9-10 tahun berjumlah 12 orang (60\%).

Gambaran umum jenis kelamin responden diruangan anak dirumah sakit sultan imanuddin pangkalan bun. Jenis kelamin responden berdasarkan jumlah responden diruangan anak, yang dibedakan menjadi dua macam dapat dilihat pada tabel 2

Tabel 2 Distribusi responden berdasarkan jenis kelamin

\begin{tabular}{cccc}
\hline No & $\begin{array}{c}\text { Jenis } \\
\text { kelamin }\end{array}$ & Jumlah & Presentase \\
\hline $\mathbf{1}$ & Perempuan & 11 & $55 \%$ \\
$\mathbf{2}$ & Laki-laki & 9 & $45 \%$ \\
$\mathbf{3}$ & Total & 20 & $100 \%$ \\
\hline
\end{tabular}

Dari tabel diatas diketahui sebagian besar dari responden berjenis kelamin perempuan berjumlah 11 orang $(55 \%)$. 
Gambaran umum pendidikan berdasarkan jumlah responden dirunagan anak dapat dilihat pada tabel 3

Tabel 3 Distribusi responden berdasarkan pendidikan

\begin{tabular}{cllc}
\hline No & Pendidikan & Jumlah & Presentase \\
\hline $\mathbf{1}$ & TK & 7 & $35 \%$ \\
$\mathbf{2}$ & SD & 13 & $65 \%$ \\
$\mathbf{3}$ & Total & 20 & $100 \%$ \\
\hline
\end{tabular}

Dari tabel diatas diketahui sebagian besar dari responden masih bersekolah SD berjumlah 13 orang (65\%).

\section{Data Khusus}

\section{Berdasarkan Kualitas Tidur Anak Sebelum Diberikan Terapi Pijat Refleksi Kaki.}

Tabel 4 Distribusi kualitas tidur sebelum dilakukan terapi pijatan refleksi kaki.

\begin{tabular}{cccc}
\hline No & Kategori & Jumlah & Presentase \\
\hline $\mathbf{1}$ & Sangat baik & 0 & $0 \%$ \\
$\mathbf{2}$ & Baik & 0 & $0 \%$ \\
$\mathbf{3}$ & Kurang & 9 & $45 \%$ \\
$\mathbf{4}$ & Sangat kurang & 11 & $55 \%$ \\
$\mathbf{5}$ & Total & 20 & $100 \%$ \\
\hline
\end{tabular}

Dari tabel diatas sebelum dilakukan tindakan terapi pijat relaksasi kaki diketahui responden yang mengalami kualitas tidur sebagian besar sangat kurang sebanyak 11 orang (55\%).

\section{Berdasarkan Kualitas Tidur Anak Sesudah Dilakukan Terapi Pijat Refleksi Kaki.}

Tabel 5 Distribusi kualitas tidur sesudah dilakukan terapi pijatan refleksi kaki.

\begin{tabular}{cccc}
\hline No & Kategori & Jumlah & Presentase \\
\hline $\mathbf{1}$ & Sangat baik & 3 & $15 \%$ \\
$\mathbf{2}$ & Baik & 12 & $60 \%$ \\
$\mathbf{3}$ & Kurang & 0 & $0 \%$ \\
$\mathbf{4}$ & Sangat kurang & 5 & $25 \%$ \\
$\mathbf{5}$ & Total & 20 & $100 \%$ \\
\hline
\end{tabular}

Dari tabel diatas sesudah dilakukan tindakan terapi pijat relaksasi kaki diketahui responden yang mengalami kualitas tidur sebagian besar baik sebanyak 12 orang $(60 \%)$.

Berdasarkan data dari hasil penelitian pengaruh terapi pijat refleksi kaki terhadap kualitas tidur pada anak usia 6-10 tahun di Rumah Sakit Sultan Imanuddin Pangkalan Bun dapat digambarkan sebagai berikut:

\begin{tabular}{ccccc}
\hline & \multicolumn{4}{c}{ Rank Spearman Test } \\
\cline { 2 - 5 } Kategori & \multicolumn{3}{c}{ Perlakuan (sebelum dan Sesudah) } \\
& $\begin{array}{c}\text { Sebelu Presentas Sesudah } \\
\mathrm{m}\end{array}$ & $\mathrm{e}$ & & $\mathrm{e}$ \\
Sangat baik & 0 & $0 \%$ & 3 & $15 \%$ \\
Baik & 0 & $0 \%$ & 12 & $60 \%$ \\
Kurang & 9 & $45 \%$ & 0 & $0 \%$ \\
$\begin{array}{c}\text { Sangat } \\
\text { kurang }\end{array}$ & 11 & $55 \%$ & 5 & $25 \%$ \\
& Hasil uji Rank Spearman \\
$\boldsymbol{p}=\mathbf{0 , 0 3 3}$ \\
\hline
\end{tabular}

Berdasarkan tabel 6 menunjunkan bahwa sebagian besar responden sebelum diberikan pijat refleksi kaki terhadap kualitas tidur pada anak sangat kurang sebanyak 11 orang (55\%) responden dan setelah diberikan pijat refleksi kaki kualitas baik sebanyak 12 orang $(60 \%)$.

\section{PEMBAHASAN}

Setelah dilakukan analisis data dan menguji hasil penelitian dengan menggunakan uji statistik rank spearman hasil signifikan sebelum dan sesudah diberikan tindakan pijat refleksi kaki sehingga memerlukan pembahasan tentang "Pengaruh Pijat Refleksi Kaki Terhadap Kualitas Tidur Pada Anak Usia 6-10 Tahun Di Rumah Sakit Sultan Imanuddin Pangkalan Bun". 


\section{Kualitas Tidur Sebelum Dilakukan Terapi Pijat Refleksi Kaki}

Dari penelitian ini responden yang diteliti terlebih dahulu dijelaskan manfaat dari pijat refleksi kaki , sebelum dilakukan terapipijat refleksi kaki. Seluruh responden yang menagalami kualitas tidur kurang sebanyak 20 orang (100\%).

Hospitalisasi merupakan pengalaman yang mengancam bagi setiap orang. Penyakit yang diderita akan menyebabkan perubahan perilaku normal sehingga klien perlu menjalani perawatan, hospitalisasi menimbulkan dampak pada beberapa aspek sebagai berikut (Asmadi,2008): Privasi dapat diartikan sebagai refleksi perasaan nyaman pada diri seseorang dan bersifat pribadi. Bisa dikatakan, privasi adalah suatu hal yang sifatnya pribadi. Sewaktu dirawat di rumah sakit, klien kehilangan sebagai privasinya.

Gaya hidup juga dapat mempengaruhi karena klien yang dirawat di rumah sakit sering kali mengalami perubahan pola gaya hidup. Hal ini disebabkan oleh perubahan kondisi antara rumah sakit dengan rumah ztempat tinggal klien, juga oleh perubahan kondisi keehatan klien. Aktivitas hidup yang klien jalani sewaktu sehat tentu berbeda dengan aktivitas yang dialaminya selama di rumah sakit. Perubahan gaya hidup akibat hospitalisasi inilah yang harus menjadi perhatian setiap perawat. Asuhan keperawatan yang diberikan harus diupayakan sedemikian rupa agar dapat menghilangkan atau setidaknya meminimalkan perubahan yang terjadi.

Otonomi dapat berpengaruh karena seperti yang telah dijelaskan sebelumnya bahwa individu yang sakit da dirawat di rumah sakit berada dalam posisi ketergantungan. Artinya, ia akan pasrah terhadap tindakan apapun yang dilakukan oleh petugas kesehatan demi mencapai keadaan sehat. Ini meniunjukkan bahwa klien yang dirawat di rumah sakit akan mengalami perubahan otonomi. Untuk mengatasi perubahan ini, perawat harus selalu memberitahu klien sebelum melakukan intervensi apapun dan melibatkan klien dalam intervensi, baik secara aktif maupun pasif.

Peran dapat diartikan sebagai seperangkat perilaku yang diharapkan individu sesuai dengan status sosialnya. Jika ia seorang perawat, peran yang diharapkan adalah peran sebagi perawat bukan sebagai dokter.Selain itu, peran yang dijalani seseorang adalah sesuai dengan status kesehatannya. Peran yang dijalani sewaktu sehat tentu berbeda dengan peran yang dijalani saat sakit.Tidak mengherankan jika klien yang dirawat di rumah sakit mengalami perubahan peran. Perubahan yang terjadi tidak hanya pada diri pasien, tetapi juga pada keluarga.

Dari salah satu dampak hospitalisasi pada anak dapat menimbulkan kualitas tidur pada anak yang kurang sehingga nantinya akan menggangu dlam proses penyembuhan karena ketika anak kualitas tidurnya baik nantinya akan membantu dalam proses penyembuhan.

\section{Kualitas Tidur Sesudah Dilakukan Terapi Pijat Refleksi Kaki}

Sesuai dengan analisa dan interpeatsi yang dilakukan pada 20 responden mengenai kualitas tidur diruangan anak Ruamah Sakit Sultan Imanuddin Pangkalan Bun, hampir dari keseluruhan responden mengalami 
kualitas tidur yang baik yaitu sebanyak 12 orang (60\%).

Peneliti berasumsi ada keserasian antara teori dan kenyataan Pijat refleksi kaki memberikan efek yang positif ketika pemijatan dilakukan sesuai dengan titik dengan keluhan responden yaitu mengenai kualitas tidur yang kurang sehingga dapat meningkatkan kualitas tidur.

Teori Endorphin Pommeranz menyatakan bahwa tubuh akan bereaksi dengan mengeluarkan endorphin karena pemijatan. Endorphin adalah zat yang diproduksi secara alamiah oleh tubuh, bekerja, serta memiliki efek seperti morphin. Endorphin bersifat menenangkan, memberikan efek nyaman, dan sangat berperan dalam regenerasi sel-sel guna memperbaiki bagian tubuh yang sudah using atau rusak. Pijat refleksi juga memberikan manfaat bagi sistem dalam tubuh (Hendro dan Yusti, 2015).

\section{Pengaruh Pijat Refleksi Kaki Terhadap Kualitas Tidur Anak 6-10 Tahun}

Hasil pengujian statistik dengan menggunakan Rank Spearman Tes diperoleh nilai $\mathrm{P}=0,033$ (lihat lampiran) pada penelitian ini digunakan derajat eror $\alpha<0,05$. P dibanding nilai $\alpha$ diperoleh $\mathrm{P}<\alpha$, maka Ho ditolak dan $\mathrm{H} 1$ diterima artinya ada Pengaruh Pijat Refleksi Kaki Terhadap Kualitas Tidur Pada Anak Usia 6-10 Tahun di Rumah Sakit Sultan Imanuddin Pangkalan Bun.

Bahwa dari hasil pemijatan refleksi kaki menghasilkan hormon endorphin yang memberikan efek yag menenangkan dan memeberika rasa nyaman dan dapat berpengaruh terhadap kualitas tidur.

\section{KESIMPULAN DAN SARAN}

\section{Kesimpulan}

1. Sebelum diberikan terapi pijat refleksi kaki hampir seluruh responden kualitas tidurnya kurang dan sebagian besar kualitas tidur sangat kurang.

2. Sesudah diberikan terapi pijat refleksi kaki ternyata terjadi peningkatan terhadap kualitas tidur responden sebagian besar kualilitas tidurnya baik.

3. Ada pengaruh pijat refelksi terhadap kualitas tidur anak yang sedang menjalani rawat inap di Rumah sakit Sultan Imanuddin Pangkalan Bun.

\section{Saran}

Berdasarkan kesimpulan dari hasil penelitian, maka peneliti mengajukan saran yang ditunjukan kepada:

\section{Bagi responden}

Memberikan solusi penangan terhadap kualitas tidur anak yang menggunakan terapi pijat refleksi kaki,sehingga dapat menimbulkan dampak positif terhadap kua anak, kualitas tidur sangatlah penting bagi anak karena tidur merupakan sebagai kebutuhan dasar manusia ketika anak mengalami kualitas tidur yang kurang maka dapat menggangu baik itu kesehatan maupun aktifitasnya.

2. Bagi rumah sakit

Terapi keperawatan pijat refleksi kaki cukup bagus digunakan sebagai salah satu terapi untuk mengatasi masalah kualitas tidur pada khususnya anak dan dapat dijadikan refrensi program terapi untuk 
mengatasi kualitas tidur khususnya diruangan anak yang dapat meningkatkan kualitas tidur anak.

3. Bagi peneliti selanjutnya

Bagi peneliti yang ingin mengambil penelitian selajutnya tentang terapi keperawatan komplementer khususnya terapi pijat refleksi kaki dapat sebagai referensi untuk melakukan terapi mengenai pijat refleksi kaki yang nanti dapat dikembangkan lebih lanjut seperti terapi pijat refleksi kaki untuk mengurangi nyeri dan menurunkan tekanan darah.

\section{DAFTAR PUSTAKA}

Asmadi. 2008. "Teknik Prosedur Keperawatan: Konsep dan Aplikasi Kebutuhan dasar Klien”. Jakarta:Salemba Medika.

Hendro dan Yustri. 2010. "Ilmu Pijat Pengobatan Refleksi Relaksasi”. Jakarta: Direktorat Pembinaan Kursus dan Pelatihan.

Kementerian Pemberdayaan

Perempuan dan Perlindungan Anak (KPP\& PA). 2015. Jakarta.

Kemenkes RI. 2015."Profil Kesehatan Indonesia Tahun 2015". Jakarta: Kementrian Kesehatan Republik Indonesia,

Notoarmodjo, S. 2014. "Metode Penelitian kesehatan”. Jakarta: Rineka Cipta.

Potter dan Perry. 2005. "Buku Ajar Fundamental Keperawatan: Konsep Proses Praktis (Renata Komalasari et al,penerjemah) Ed ke 4. Jakarta. EGC. 